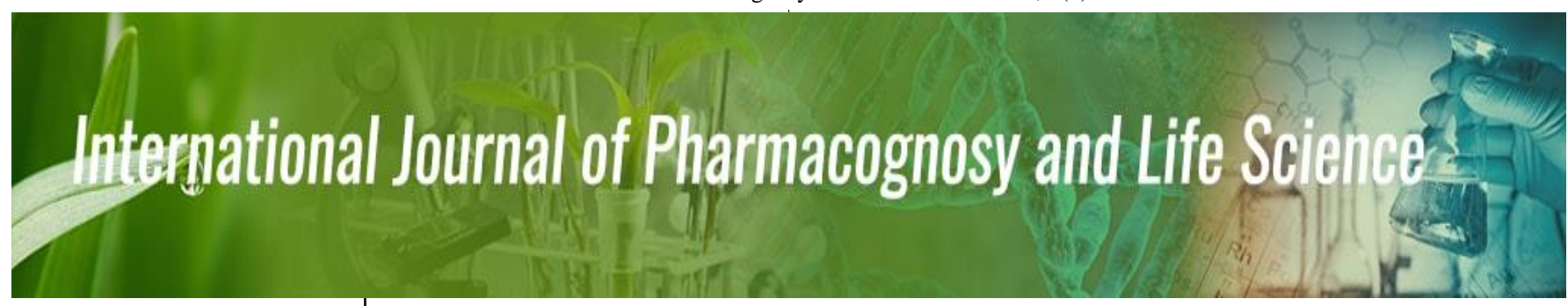

E-ISSN: 2707-2835

P-ISSN: 2707-2827

www.pharmacognosyjournal.com IJPLS 2021; 2(1): 28-33

Received: 12-11-2020

Accepted: 19-12-2020

\section{Pankaj Singh}

Research Scholar, Department

of Pharmacology, Advance

Institute of Biotech and

Paramedical Sciences Kanpur,

Uttar Pradesh, India

\section{Mamta Tiwari}

Associate Professor,

Department of Pharmacology,

Advance Institute of Biotech

and Paramedical Sciences

Kanpur, Uttar Pradesh, India
Corresponding Author:

Pankaj Singh

Research Scholar, Department of Pharmacology, Advance

Institute of Biotech and

Paramedical Sciences Kanpur,

Uttar Pradesh, India

\section{Review on Azadirachta Indica}

\section{Pankaj Singh and Mamta Tiwari}

DOI: https://doi.org/10.33545/27072827.2021.v2.i1a.24

\begin{abstract}
Neem has become important in the global context today because it offers answers to the major concerns facing mankind. Azadirachta indica is a fast growing evergreen popular tree found commonly in India, Africa and America. This review gives a bird's eye view mainly on the biological activity and its preventive-promotive medicinal uses and applications over all this review also tell you that how the "neem is the one solution of thousand problems", like Antiallergenic, antidermatic, antifeedent, antifungal, anti- inflammatory, antipyretic, antiscabic, cardiac, diuretic, insecticidal, parricidal, nematicidal, spermicidal and other biological activities.
\end{abstract}

Keywords: Neem, Azadirachta Indica, Activity, Azadirachtin, Uses, Nimbidin

\section{Introduction}

Azadirachta indica is a fast growing evergreen popular tree found commonly in India, Africa and America ${ }^{[1]}$. It has been used in ayurvedic medicine for more than 4000 years due to its medicinal properties. Neem is called 'arista' in Sanskrit a word that means 'perfect, complete and imperishable' ${ }^{[2]}$. Arishtha is the sanskrit name of the neem tree meaning 'reliver of sickness' and hence is considered as 'Sarbarogaribarini'. The tree is regarded as 'village dispensory' in India. The importance of the neem tree has been recognised by the US National Academy of Sciences, which publish a report in 1992 entiteled 'Neem- a tree for solving global problems' ${ }^{[3]}$.

It grows in much of Southeast Asia and West Africa; a few trees have recently been planted in the Carribbean and several Central American countries, including Mexico. The people of India have long revered the neem tree; for centuries, millions have cleaned their teeth with neem twigs, smiered skin disorders with neem-leaf juice, taken neem tea as a tonic, and placed neem leaves in their beds, books, grainbins, cupboard and closets to keep away troublesome bugs ${ }^{[4]}$. The number of benefits of neem is listed in ancient documents like 'Charak-Samhita' and 'Susruta-Samhita'. It is commonly called 'Indian Lilic' or 'Margosa', belongs to the family Meliaceae, subfamily Meloideae and tribe Melieae. Neem is the most versatile, multifarious trees of tropics, with immense potential. It possesses maximum useful non-wood products (leaves, bark, flowers, fruits, seed, gum, oil and neem cake) than any other tree species. Known to have antiallergenic, antidermatic, antifeedent, antifungal, antiinflammatory, antipyorrhoeic, antiscabic, cardiac, diuretic, insecticidal, larvicidal, nematicidal, spermicidal and other biological activities. Because of these activities neem has found enormous applications making it a green treasure ${ }^{[3]}$.

Neem has become important in the global context today because it offers answers to the major concerns facing mankind. Neem (Azadirachta indica) is considered harmless to humans, animals, birds, beneficial insects and earthworms, and has been approved by the US Environmental Protection Agency for use on food crops ${ }^{[5]}$. Neem (Azadirachta indica) of family meliaceae is evergreen tree of potential medicinal value found in most tropical countries ${ }^{[6]}$. Biologically active principles isolated from different parts of the plant include: azadirachtin, meliacin, gedunin, salanin, nimbin, valassin and many other derivatives of these principles. Meliacin forms the bitter principles of neem seed oil, the seed also contain tignic acid (5-methyl-2-butanic acid) responsible for the distinctive odour of the oil. These compounds belong to natural products called triterpenoids (Limonoids). The active principles are slightly hydrophilic, but freely lipophilic and highly soluble in organic solvents like hydrophilic, alcohols, ketones and esters ${ }^{[7]}$. 


\section{Origin and Distribution of Neem}

Two species of Azadirachta have been reported, Azadirachta indica

- Juss-native to Indian subcontinent and Azadirachta excelsa

Kack- confined to Philippines and Indonesia.

Neem is a member of the Mahogany family.

Table 1: Taxonomic position of neem

\begin{tabular}{|c|c|}
\hline Order & Rutales \\
\hline Suborder & Rutinae \\
\hline Family & Meliaceae \\
\hline Subfamily & Melioideae \\
\hline Tribe & Melieae \\
\hline Genus & Azadirachta \\
\hline Species & Indica \\
\hline
\end{tabular}

There are an estimated 25 million trees growing all over India(15) of which $5.5 \%$ are found in Karnataka and it is in the third place next to Uttar Pradesh (55.7\%) and Tamilnadu $(17.8 \%)$ occupying the first two places respectively. The other states of India where neem tree is found growing includes Andhra Pradesh, Assam, Bihar, Delhi, Gujarat, Haryana, Himachal Pradesh, Kerala, Madhya Pradesh, Maharashtra, Meghalaya, Orissa, Punjab, Rajasthan, West Bengal along with Andaman and Nicobar Islands, the Union territory. India stands first in neem seed production and about 4,42,300 tons of seeds are produced annually yielding 88,400 tons of neem oil and 3,53,800 tons of neem cake ${ }^{[2]}$

Nimbidin, a major crude bitter principle extracted from the oil of seed kernels of Azadirachta indica demonstrated several biological activities. From this crude principle some tetranortriterpenes, including nimbin, nimbinin, nimbidinin, nimbolide and nimbidic acid have been isolated [3]. Nimbidin and sodium nimbidate possess significant dose dependent anti-inflammatory activity against carrageenin induced acute paw oedema in rats and formalin-induced arthritis ${ }^{[8,9]}$.

A significant antiulcer effect was observed with nimbidin in preventing acetylsalicylic acid, indomethacin, stress or serotonin- induced gastric lesions as well as histamine or cysteamine-induced duodenal ulcers [12, 13]. Oral administration of nimbidin demonstrated significant hypoglycaemic effect in fasting rabbits ${ }^{[11]}$. Nimbidin can also suppress basal as well as histamine and carbacholstimulated gastric acid output and may act as an antihistamine by blocking $\mathrm{H}_{2}$ receptors, thereby helping as an antiulcer agent. The spermicidal activity of nimbidin and nimbin was reported in rats and human as early as $1959^{[12]}$. Nimbidin also demonstrated antifungal activity by inhibiting the growth of Tinea rubrum. In vitro, it can completely inhibit the growth of Mycobacterium tuberculosis and was also found to be bactericidal ${ }^{[15]}$. Diuretic activity was also reported for sodium nimbidinate in dogs ${ }^{[16]}$.

Nimbolide show antimalarial activity by inhibiting the growth of Plasmodium falciparum ${ }^{[19]}$. Nimbolide also shows antibacterial activity against $S$. aureus and $S$. coagulase ${ }^{[20,21]}$. Gedunin isolated from neem seed oil has been reported to possess both antifungal ${ }^{[22]}$ and antimalarial acivities [21]. Azadirachtin, a tetranortriterpenoid plant limonoid which can be isolated from the seeds of the neem tree. Azadirachtin is a common example of a natural plant defence chemical affecting feeding, through chemoreception (primary antifeedancy), that consists in the blockage of the input from receptors that normally respond to phagostimulants, or from stimulation of specific deterrent cells or both and through a reduction in food intake due to toxic effects if consumed (secondary antifeedancy), where food intake is reduced after application of azadirachtin in ways which bypass the mouth part chemoreceptors. Antifeedancy can be accessed from crude to refined neem extracts to neem enriched extracts to pure azadirachtin. Lepidoptera show effective sensitivity to azadirachtin with antifeedant effects at concentrations ranging between 1 and $50 \mathrm{ppm}$. Azadirachtin has also growth regulatory effects on larval insects like disruption of moulting, growth inhibition, malformation, which may contribute to mortality. This is attributed to a disruption of endocrine events as the downregulation of haemolymph ecdysteroid level through the blockage of release of PTTH, prothoracicotropic hormone, from the brain-corpus cardiacum complex, or to a delay in the appearance of the last ecdysteroid peak showing a complete moult inhibition. There are also effects on allatropin and juvenile hormone titres ${ }^{[32]}$.

Mahmoodin, a deoxygedunin isolated from seed oil, has been shown to possess moderate antibacterial action against some strains of human pathogenic bacteria ${ }^{[23]}$. Condensed tannins from the bark contain gallic acid, $(+)$ gallocatechin, $(-)$ epicatechin, $(+)$ catechin and epigallocatechin, of which gallic acid, (-) epicatechin and catechin are primarily responsible for inhibiting the generation of chemiluminescence by activated human polymorphonuclear neutrophil (PMN) ${ }^{[24]}$, indicating that these compounds inhibit oxidative burst of PMN during inflammation. Three tricyclic diterpenoids, margolone, margolonone and isomargolonone isolated from neem stem bark are active against Klebsiella, Staphylococcus and Serratia species ${ }^{[25]}$. Sulphur-containing compounds such as cyclic trisulphide and tetrasulphide isolated from the steam distillate of fresh, matured neem leaves have antifungal activity against Trichophyton mentagrophytes ${ }^{[26]}$.

Polysaccharides from neem exhibit various biological effects. A polysaccharide extracted from bark inhibits carrageenin-induced inflammation in mouse ${ }^{[27]}$. Two watersoluble polysaccharides GIa and GIB isolated from the bark of Melia azadirachta, demonstrated strong antitumour effect with complete regression of the tumours, when administered in mice at a daily dose of $50 \mathrm{mg} / \mathrm{kg}$ for four days from $24 \mathrm{~h}$ after subcutaneous inoculation of Sarcoma-180 cells ${ }^{[28]}$. Two more polysaccharides, GIIa and GIIIa isolated from M. azadirachta bark also showed significant anti-inflammatory effect on carrageenin-induced oedema in mice ${ }^{[29]}$. Two polymers isolated from an aqueous extract of neem bark possess anticomplement activity, amongst which the compound NB-II, a peptidoglycan of lower molecular weight was found to be more potent 30,31. Some active ingredients (phytosterol fraction) isolated from the lipid part of neem fruits, exhibit antiulcer activity in stress induced gastric lesions 32. an aqueous extract of neem bark possess anticomplement activity, amongst which the compound NBII, a peptidoglycan of lower molecular weight was found to be more potent 30,31. Some active ingredients (phytosterol fraction) isolated from the lipid part of neem fruits, exhibit antiulcer activity in stress induced gastric lesions 32 an aqueous extract of neem bark possess anticomplement activity, amongst which the compound NB-II, a peptidoglycan of lower molecular weight was found to be 
more potent30,31. Some active ingredients (phytosterol fraction) isolated from the lipid part of neem fruits, exhibit antiulcer activity in stress induced gastric lesions 32 .

\section{Medicinal Uses of Neem}

Neem is well-known for its durable wood. In addition, the non-wood products of neem like flowers, fruits, seeds (oil, cake), leaves (Figure 2), bark and gum also find various uses. The antifungal, antibacterial, insecticidal and other versatile biological activities of these products are well established 2, Some of the medicinal attributes of various parts of neem as mentioned in ayurveda have been summarized in Table 2 .

Table-2 [3]

\begin{tabular}{|c|c|}
\hline Part & Medicinal uses \\
\hline Leaf & Leprosy, eye problem, epistaxis, intestinal worms, anorexia, biliousness, skin ulcers. \\
\hline Bark & Analgesic, alternative and curative of fever. \\
\hline Flower & Bile suppression, elimination of intestinal worms and phlegm. \\
\hline Fruit & $\begin{array}{l}\text { Relieves piles, intestinal worms, urinary disorder, epistaxis, phlegm, eye problem, diabetes, } \\
\text { wounds and leprosy. }\end{array}$ \\
\hline Twig & $\begin{array}{l}\text { Relieves cough, asthma, piles, phantom tumour, intestinal worms, spermatorrhoea, } \\
\text { obstinate urinary disorder, diabetes. }\end{array}$ \\
\hline Gum & Effective against skin diseases like ringworms, scabies, wounds and ulcers \\
\hline Seed pulp & Leprosy and intestinal worms \\
\hline Oil & Leprosy and intestinal worms. \\
\hline Root, bark, leaf, flower and fruit together & Blood morbidity, biliary afflictions, itching, skin ulcer, burning sensation and leprosy. \\
\hline
\end{tabular}
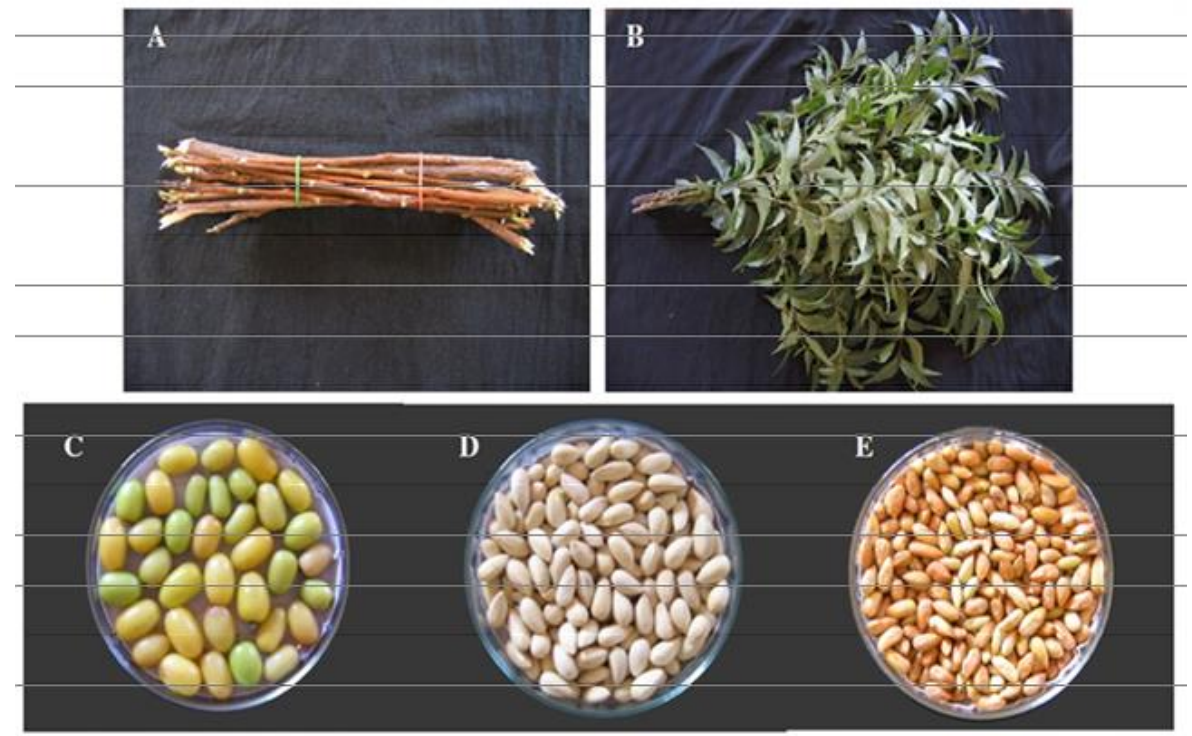

Fig-A = Twigs, Fig-B = Leaves, Fig-C = Fruits, Fig-D = Seeds (with endocarp), Fig-E = Seeds (without endocarp) ${ }^{[2]}$

There has been astronomical increase in the costs of fertilizers, pesticides, animal feeds and drugs in the developing countries, with an increasing indebtedness and acute poverty. This situation exerts enormous pressure to explore local resources handy to combat these deficits and improve quality of life of the people. One of such available resources with great potentials in the 21 st century is the neem tree.

The objectives of these reviews were to: elucidate the premises of neem for exploitation and utilization; identify formulations of biologically active principles, limitations against wide spread use and possible inherent dangers of neem products ${ }^{[7]}$.

\section{Afforestation}

The large scale plantation of neem trees help to combat desertification, deforestation, soil erosion and to reduce excessive global warming. Neem has high rate of photosynthesis and librates more oxygen than many other tree species, thus purifying the atmosphere. Neem products have water purifying activity. Neem leaf powder could be used as biosorbent for the removal of dyes like congo red from water.

The temperature under the neem has been found to be 10degree centigrate less than the surrounding temperature, during hot summer months in the northern parts of india. In agroforesty, neem products benefits extended to providing shade, firewood, timber, windbreaks, shelter belt and check against desertification in the semi-arid zone of northern Nigeria. Neem has the ability of re-sprout after cutting and to re-grow its canopy after pollarding. Thus it is highly suited for pole production. In Saudi Arabia neem plantation when full grown is expected to provide shade to about two million pilgrims. In Nigeria, neem forms about $90 \%$ of the trees in the foresty plantations established in the 12 states with in the savanna zone under the affortations programme [33].

\section{Chemotherapeutic effect of neem}

In West Africa, India, Burma, etc., both aqueous and alcohol extracts of bark and leaves of neem are effective anti-malaria agents, particularly on chloroquine resistant 
strains, One active components, 'gedunin' gave significant control as effective as quinine on malaria. The mechanism is possibly redox status of red blood cells (RBC) on parasite. The plasmodial parasite generates oxidant, while neem extracts reduced the oxidized cells to destroy the malaria parasite.Furthermore, neem barks and leaves posses strong antiseptic property warranting use as active ingredient in tooth paste in India and Germany. While aqueous extract of leaves exhibit laxative potentials by increased bowel movement.

\section{Male antifertility activity}

The Neem seed oil (NSO) and leaf extracts act as powerful spermicide and significantly inhibited spermatogenesis, decreased sperm motility, count and cessation of fertility. These conditions were reversed by the withdrawal of neem products 4 - 6 weeks later. No significant effect on loss of libido or potency. Furthermore, NSO possess antiimplantation and abortifacient properties. Sinha et al. (1984) found spermatozoa of human and rhesus monkey were immotile and die within 30 min of contact with NSO in an intravaginal dose of $1 \mathrm{~mL}$. Vaginal biopsy revealed no side effect, while radio-isotope studies indicate non-absorption in the vagina and non-antiovulatory (Sinha et al., 1984). These findings enabled neem oil formulation 'sensal' use in India as powerful contraceptive ${ }^{[7]}$.

\section{Neem extract as a corrosion inhibitor}

The corrosion of metals in many industries, constructions, installations, and civil services such as electricity, water, and sewage supplies is a serious problem. In order to prevent or minimize corrosion, inhibitors are usually used especially in flow cooling systems. Organic, inorganic, or a mixture of both inhibitors can inhibit corrosion by either chemisorptions on the metal surface or reacting with metal ions and forming a barrier-type precipitate on its surface. Because of the toxic nature and/or high cost of some chemicals currently in use as inhibitors, it is necessary to develop environmentally acceptable and inexpensive ones. The effect of aqueous extract of UAE Neem (Azadirachta Indica) on the corrosion inhibition of carbon steel in $1.0 \mathrm{MHCl}$ solution was investigated electrochemically, and by weight-loss experiments at temperatures ranging from 303 to $343 \mathrm{~K}$. The percentage inhibition increased with the increase of the concentration of the inhibitor. At a concentration of $2.0 \mathrm{~g} / \mathrm{L}$, the percentage inhibition reached about $87 \%$ at room temperature and $80 \%$ at $303 \mathrm{~K}$. The percentage inhibition decreased with the increase of temperature. The thermodynamic parameters for the adsorption of this inhibitor on the metal surface were calculated using the Temkin adsorption isotherm. The aqueous Neem leaves extract was found to be an excellent potential corrosion inhibitor because of the high content of tannin content as well as the presence of a series of complex triterpene glycosides ${ }^{[34]}$

\section{Neem oil as a diesel fuel in c.i engine}

An enormous increase in the number of automobiles in recent years has resulted in greater demand for petroleum products. With crude oil reserves estimated to last only for a few decades, therefore, effort are on way to research now alternatives to diesel. Depletion of crude oil would cause a major impact on the transportation sector. Of the various alternate fuels under consideration, biodiesel, derived from esterified vegetable oils, appears to be the most promising alternative fuel to diesel due to the following reasons.

- Biodiesel can be used in the existing engines without any modifications.

- Biodiesel obtained from vegetable sources does not contain any sulfur, aromatic hydrocarbons, metals or crude oil residues.

- Biodiesel is an oxygenated fuel; emissions of carbon monoxide and soot tend to reduce.

- Unlike fossil fuels, use of Biodiesel does not contribute to global warming as the $\mathrm{CO}_{2}$ so produced absorbed by the plants. Thus in nature $\mathrm{CO}_{2}$ is balanced.

- The Occupational Safety and Health Administration classify biodiesel as a non-flammable liquid.

- The use of biodiesel can extend the life span of diesel engines because it is more lubricating than petroleum diesel fuel.

- Biodiesel is mostly obtained from renewable vegetable oils/animal fats and hence it may improve the fuel or energy security and thus leading to economy independence.

K. Anbumani and Ajit Pal Singh studied the feasibility of using two edible plant oils mustard (Brassica nigra, Family: Cruciferae) and neem (Azadirachta indica, Family: Meliaceae) as diesel substitute a comparative study on their combustion characteristics on a C.I. engine were made. Oils were esterified (butyl esters) before blending with pure diesel in the ratio of 10:90, 15:85, 20:80, and 25:75 by volume. Pure diesel was used as control. Studies have revealed that on blending vegetable oils with diesel a remarkable improvement in their physical and chemical properties was observed. Cetane number came to be very close to pure diesel. Engine (C.I.) was run at different loads $(0,4,8,12,16$, and $20 \mathrm{~kg})$ at a constant speed (1500 rpm) separately on each blend and also on pure diesel. Results have indicated that engine run at $20 \%$ blend of oils showed a closer performance to pure diesel. However, mustard oil at $20 \%$ blend with diesel gave best performance as compared to neem oil blends in terms of low smoke intensity, emission of $\mathrm{HC}$ and NO. All the parameters tested viz., total fuel consumption, specific energy consumption; specific fuel consumption, brake thermal efficiency and cylindrical peak pressure were improved. These studies have revealed that both the oils a $20 \%$ blend with diesel can be used as a diesel substitute. Further, esterified mustard oil at 20\% blend satisfies the important fuel properties as per ASTM specifications of biodiesel as it lead to an improvement in engine performance and emission characteristics without bringing any modifications in the engine ${ }^{[3]}$.

Effect of Neem Oil on Sperm Mitochondrial Activity Indigenously available neem oil in its natural form has spermicidal and anti-implantation effect. Two derivatives of neem oil - sodium nimbinate and sodium nimbidinate have been found to possess weak spermicidal action in vitro. It was found that neem oil decreases sperm motility instantly. In view of this, Prashant Patil and Gaikwad RD studied to find the effect of neem oil on sperm mitochondrial activity. It is a known fact that neem oil has some effect on motility of sperm. Motility of sperm depends on mitochondrial activity present in mid- piece of sperm. In the present study, the mitochondrial activity of sperm was evaluated after treating semen with the different quantities of neem oil. The 
mitochondrial activity was also evaluated after subjecting the semen samples for different incubation periods keeping the quantity of semen as well as that of neem oil same.

Tests were done on thirty normozoospermic semen samples with motile score more than $75 \%$. It was found that as the quantity of neem oil increases, the mitochondrial activity decreases significantly $(\mathrm{P}<0.001)$. Similar results were found, when same quantity of neem oil was treated with same quantity of semen, but incubating for different time durations. The mitochondrial activity decreases significantly $(\mathrm{P}<0.001)$ from one minute to twenty minutes. So, it indicates that as the contact period between neem oil and semen increases the mitochondrial activity decreases significantly ${ }^{[36]}$.

\section{Anti-inflammatory, antipyretic and analgesic activities} Pyrexia is delineated as the raised of body degree of heat. It is the body's natural defense to exhibit a habitat where contagious factors or impair tissue can't outlive. Normally the contagious or impair tissue introduce the augmented production inflammatory agents including cytokines like interleukin $1 \beta, \alpha, \beta$ and TNF- $\alpha$. These intercessor raised prostaglandin elements (PGE2) forthcoming hypothalamic region and thereby activate the hypothalamic to raised body. ${ }^{[27]}$ The chloroform extract of stem bark is effective against carrageenin- induced paw oedema in rat and mouse ear Inflammation. Inflammatory stomatitis in children is cured by the bark extract.

\section{Antitumor and antiviral activities}

Plants, vegetables and herbs used as food and in the folk and traditional medicine have been accepted currently as one of the main source of cancer chemoprevention drug discovery and development. Despite a number of plant extracts used against diseases in traditional medicine, only a few of them have been scientifically explored. Azadirachta indica (family name: Meliaceae, common names: lilac, margosa tree, neem and neem chal) has been used successfully for centuries to reduce tumors by herbalists throughout Southeast Asia ${ }^{[26]}$.

Researchers in India, Europe and Japan have now found that polysaccharides and limonoids found in neem bark, leaves and seed oil reduced tumors and cancers and showed effectiveness against lymphocytic leukemia. Mitotic inhibition activity by the leaf extract was observed. In vitro activity against sarcoma 180 ascites tumor by intraperitoneal administration of polysaccharides from the bark was reported. Several reports have also highlighted the pronounced antiviral efficacy of aqueous extract (aq. ext.) of neem leaves (NL) against Small pox, Fowl pox, Polio and HSV as assessed by virus inhibition assay (98-100). Aqueous extract of Neem leaf and a fraction from neem oil (NIM-76) have also been reported to suppress HIV and Polio viruses.

\section{Antiulcer activity}

Azadirachta indica A. Juss, commonly known as "Neem," has been extensively used in India as an ayurvedic medicine for the treatment of various diseases, such as, leprosy, intestinal helminthiasis, and respiratory disorders in children. Bandyopadhyay et al. have reported the gastroprotective property of dried bark extract of Azadirachta indica (AI) in the mercaptomethylimidazole, PL, CRU, indomethacin, AL, and HST induced ulcer models. It acts mainly by inhibiting acid secretion and blocking oxidative damage of the gastric mucosa.

\section{Neem leaf extract for the treatment of predontiti}

Neem leaf extract can help reduce bacteria and plaque levels that cause the progression of periodontitis. In 2004, the International Journal of Dentistry published a study showing that subjects using neem gel experienced periodontal improvement when compared to a control group. A study published the same year in the Journal of Ethnopharmacology revealed similar findings. To take advantage of this herb's bacteria-reducing properties, uses a mouthwash made with several drops of neem leaf extract mixed in water, and use it twice daily ${ }^{[37]}$. HK ATPase activity, while blockade of oxidative damage of gastric mucosa was evident from blocking of lipid peroxidation andscavenging of endogenous hydroxyl radical (OH). Furthermore, they compared the bark extract with known antiulcer drugs, ranitidine and omeprazole in the PL and the stress ulcer models and found that the extract was almost equipotent to the standard drugs. The bark extract exhibited more antioxidant activity than a variety of known antioxidants. Garg et al., have also reported an antiulcer effect of neem leaf extract and the prevention of mucus depletion and mast cell degranulation as possible mechanism. A phenolic glycoside has been isolated by Bandyopadhyay et al., as an active constituent, whose characterisation and mechanism are under investigation. Therefore, Azadirachta indica offers another option for a safer and an effective antiulcer.

\section{Antioxidant Compounds}

The process through which free radicals are created, is a normal function of the body but the resulting molecules are unstable and can damage other cells. A series of disorders, including cardiovascular disease, eye health, cataracts and macular degeneration, age-related neurodegeneration (decline of the brain cells and nervous system) and even cancer occurs due to high levels of free radicals. Neem protects against chemically induced carcinogens and liver damage by boosting antioxidant levels ${ }^{[29]}$.

Diabetes: With its extremely bitter properties, Neem has been used in disorders caused by overeating sweets. Recent studies have focused that Neem's hypoglycemic effect.

Liver functions: It helps to protect the liver from damage, which in turn helps to cleanse the blood. Neem leaf minimize, chemically induced liver damage by stabilizing levels of serum marker enzymes and boosting levels of antioxidants, like those found in vitamin $\mathrm{C}$ and $\mathrm{E}$ and in natural carotenoids, which neutralize free radicals and prevent damage.

Stress: Low doses of Neem leaf extracts have sedative effects. The effect disappears at high doses, approximately 400 or 800 milligrams per kilograms of body weight. It also reduces anxiety and stress.

Vitiligo: Vitiligo is believed to be an autoimmune disorder that causes patches of skin to lose its color. The dosage is of four grams of Neem leaves three times a day, ideally taken before each meal. Neem oil applied to the affected areas could aid in the reversal of discoloration. 
Viral Diseases: In India, Neem is also used to treat viral diseases such as smallpox, chicken-pox. Neem has antibacterial characteristics as well.

AIDS: Some of the best news is that Neem may help in the search for prevention or a cure for AIDS may possibly be treated by ingesting Neem leaf extracts or the whole leaf or by drinking a Neem tea ${ }^{[5]}$.

Author contribution: All author participated equally.

\section{Conflict of interest -None.}

\section{References}

1. Pingale Shirish S. Hepatoprotection study of leaves powder of Azadirachta indica A. juss, International Journal of Pharmaceutical Sciences Review and Research 2010;3(2):37-42.

2. K Girish, Bhat S Shankara. Neem - A Green Treasure, Electronic Journal of Biology 2008;4(3):102-111.

3. Biswas Kausik, Chattopadhyay Ishita, Banerjee K Ranajit and Bandyopadhyay Uday. Biological activities and medicinal properties of neem (Azadirachta indica), Current Science 2002;82(10)1336-1345.

4. Sergio Muñoz-Valenzuela, Alberto Arnoldo IbarraLópez, Luis Mariano Rubio- Silva, Humberto ValdezDávila, and Jesús Borboa-Flores. Neem Tree Morphology and Oil Content, Issues in new crops and new uses 2007, 126-128.

5. Debjit Bhowmik, Chiranjib, Jitender Yadav, KK Tripathi, KP Sampath Kumar. Herbal Remedies of Azadirachta indica and its Medicinal Application, J. Chem. Pharm. Res 2010;2(1):62-72.

6. NB Dhayanithi, TT Ajith Kumar and K Kathiresan. Effect of neem extract against the bacteria isolated from marine fish, Journal of Environmental Biology 2010;31:409-412.

7. Kabeh JD, Jalingo MGDSS. Exploiting Neem (Azadirachta Indica) Resources for Improving the Quality of Life in Taraba State, Nigeria, International Journal of Agriculture and Biology 15608530/2007/09-3-530- 532.

8. Bhargava KP, Gupta MB, Gupta GP, Mitra CR. Antiinflammatory activity of saponins and ot-her natural products. Indian J Med Res. 1970;58(6):724-730.

9. Pillai NR and Santhakumari G. Anti-arthritic and antiinflammatory actios ofnimbidin, Planta Medica 1981;43:59-63.

10. David SN, Mediscope. Anti-pyretic of Neem oil and its constituents 1969;12:25-27.

11. Pillai NR and Santhakumari G. Hypoglycemic activity of Melia azadirachta Linn (Neem), Indian Journal of Medical Research 1981;74:931-933.

12. Pillai NR and Santhakumari G. Effects of nimbidin on acute and chronic gastro-duodenal ulcer models in experimental animals, Planta Medica 1984;50:143146.

13. Pillai NR, Seshadri DS and Santhakumari G. Indian Journal of Medical Research 1978;68:169-175.

14. Sharma VN, Saxena KP. Spermicidal action of Sodium Nimbinate, Indian Journal of Medical Research 1959;47:322-324.

15. Murthy SP and Sirsi M. Pharmacological studies on Melia Azadirachta indica. Indian Journal of Physiology and Pharmacology 1958;2:387-396.
16. Bhide NK, Mehta DJ and Lewis RA. Diuretic actoin of sodium nimbidinate. Indian Journal of Medical Sciences 1958;12:141-145.

17. Jones I, Ley SV, Denholm AA, Lovell H, Wood A and Sinden RE. Sexual development of malaria parasites is inhibited in vitro by the neem extract azadirachtin and its semi-synthetic analogues, FEMS Microbiol Lett 1994;120(3):267-273.

18. Sharma VN and Saksena KP. 'sodium nimbidinate-in vitro study of its spermicidal action, Indian Journal of Medical Rearch 1959;13(12):1038-1042.

19. Rojanapo W, Suwanno S, Somaree R, Glinsukon T and Thebtaranonth Y. Screening of Antioxidants from some Thia vegetables and herbs, J. Sci. Thailand 1985;11:177-188.

20. Rochanakij S, Thebtaranonth Y, Yenjal $\mathrm{CH}$ and Yuthavong Y, Nimbolide. A constitute of Azadirachta indica inhibits plasmodium falciparum in culture, Southeast Asian J. Trop. Med. Public Health 1985;16:66-72.

21. Khalid SA, Duddeck $H$ and Gonzalez-Sierra $M$. Isolation and characterization of antimalerial agent of the neem tree, Azadirachta indica, Journal of Natural Product 1989;52:922-927.

22. Dubey Anubhav, Tiwari Mamta, Kumar Vikas, Srivastava, Kshama Singh. Akanksha. Investigation of anti-hyperlipidemic activity of vinpocetine in wistar rat International Journal of Pharmaceutical Research 2020;12(02):1879-1882.

23. Devakumar C and Sukh Dev. In Neem (eds Randhawa and Parmar, B. S.) 1996, 77-110.

24. Van der Nat, JM, Van der Sluis, WG 't Hart, LA, Van Disk et al. KTD and Labadie, R. P., Planta Med 1991;57:65-68.

25. Anubhav Dubey, Deepanshi Tiwari, Kshama Srivastava, Om Prakash, Rohit Kushwaha. A discussion on vinca plant. J Pharmacogn Phytochem 2020;9(5):2731.

26. Dubey Anubhav, Tiwari M, Singh Yatendra, Kumar N, Srivastava K. Investigation of anti-Pyretic activity of vinpocetine in wistar rat, International Journal of Pharmaceutical Research 2020;12(2):1901-1906.

27. Rao BS, Nazma and Rao MJ. Antifungal activity of gedunin, Curr. Sci 1977;46:714-716.

28. Akshay Tiwari, Shalini Singh, Anubhav Dubey and Yatendra Singh. "A preliminary study on antihyperlipidemic activity of cinnamon oil in wistar rat". International Journal of Current Research 2021;13(03):16741-16745. 